\title{
Sea-deposited mine tailings in Calancan Bay, Marinduque, Philippines: A natural laboratory for environmental mineralogy
}

\author{
R.L. MEDIANISTA ${ }^{1 *}$, E. HARMAN-TÓTH ${ }^{1}$ AND \\ T.G. WEISZBURG ${ }^{1}$ \\ ${ }^{1}$ Dept. of Mineralogy, Eötvös Loránd Univ., 1117 Budapest, \\ Hungary (*correspondence: rojamedianista@yahoo.com)
}

Submarine tailings disposal (STD) has been challenging, but controversial. Though the 1996 London Protocol (LP) permits dumping of "inert, inorganic geological material" into sea, the evaluation process prescribed by the LP doesn't contain explicitly the need of static and dynamic mineralogical characterization of the waste and the dump-site, without what the term "inert" can hardly be confirmed.

The Philippines, a Party Country of the LP, has been struggling with environmental problems caused by STD already before 1990, e.g. the Calancan Bay, Marinduque waste disposal of the porphyry copper mining of the island. At that location two USGS site observations in 2000 [1] [2] showed elevated $\mathrm{Cu}$ pore water content of limited extension in sediments, but found no mineralogical traces of acidification (e.g., presence of jarositegroup minerals; JGM).

Our current work focuses on the mineralogical processes active on/around the causeway $(\mathrm{CW})$ originally constructed by and used for the Calancan Bay STD. Analysis of satellite images shows that in the last 20 years sea currents in the shallow bay redeposited a large portion of the NW part of the $\mathrm{CW}$, forming a new sandspit between the $\mathrm{CW}$ and the near Banot Island at low tide. 39 sediment samples were collected at 17 sites using sediment core and pit sampling methods.

Laboratory work (stereo microscopy, XRD, SEM+EDX, Raman spectroscopy) confirmed that while the minerals of the CW itself remained more or less intact, the redeposited fine sediment shows acid rock drainage (ARD). On about $6500 \mathrm{~m}^{2}$ the uppermost layer of the sandspit is yellow, indicating the extensive presence of JGM, confirmed also in lab. The upper $30 \mathrm{~cm}$ of the sandspit profile consists of three layers, all the three showing evidences of different level alterations of the original sulphide minerals (pyrite, chalcopyrite). Beside JGM Fe oxyhydroxides and malachite are also present, indicating the dynamics and complexity of the running chemical processes, subject of the ongoing further research.

Support is thanked for ELTE 1783-3/2018/FEKUTSRAT Institutional Excellence Program and Koch S. Foundation.

[1] David (2002), Environ. Geol. 42, 955-965. [2] Carr et al. (2003), Aquat. Ecosyst. Health Manag. 6, 369-379. 